\title{
O ENVOLVIMENTO EMOCIONAL PARA A EQUIPE DE ENFERMAGEM:REALIDADE OU MITO?
}

\author{
Carmem Lúcia Alves Filizola* \\ Noeli Marchioro Liston Andrade Ferreira*
}

FILIZOLA, C.L.A.; FERREIRA, N.M.L.A. O envolvimento emocional para equipe de enfermagem: realidade ou mito? Rev.latino-am.enfermagem, Ribeirão Preto, v. 5, número especial, p. 9-17, maio 1997.

O presente trabalho tem como objetivo analisar o que os componentes da equipe de enfermagem de um hospital geral pensam sobre o envolvimento emocional em suas relações com o paciente. Os dados foram coletados através da aplicação de formulário aos vários integrantes da equipe de enfermagem (enfermeiro, auxiliar e atendente de enfermagem). Estes foram analisados, em um primeiro momento, separadamente por categoria funcional para, em um segundo momento, ser feita uma análise global. Pudemos a final concluir que existe na enfermagem uma política do não envolvimento, sendo o enfermeiro, ao contrário do esperado, o que mais a verbaliza. Dentre os fatores considerados negativos acarretados pelo envolvimento está o sofrimento psíquico dos integrantes da equipe. Isto nos leva a identificar o não envolvimento com o paciente como uma técnica coletiva de defesa contra o sofrimento.

UNITERMOS: envolvimento emocional, relacionamento terapêutico

\section{INTRODUÇÃO}

A Enfermagem constitui-se em um importante componente da equipe de saúde que presta assistência a pacientes internados em instituições hospitalares, uma vez que é ela que permanece as 24 horas do dia no hospital e que maior contato mantém com o paciente. Assim, por ser a enfermagem que se faz mais presente junto ao paciente internado, poderia estabelecer com ele a relação de ajuda necessária para prestar o cuidado.

A relação enfermeiro-paciente, também denominada relação de ajuda, relação de pessoa-a-pessoa ou relacionamento terapêutico, tem sido não só objeto de estudo, mas também um componente importante no discurso do ensino de enfermagem em várias áreas. Porém ela tem sido mais aprofundada nas áreas de Enfermagem em Saúde Mental e Psiquiátrica uma vez que nestas áreas se enfatiza a relação como o principal papel do enfermeiro. No entanto, tais áreas têm reconhecido também que esta forma de pensar se estenderia a toda enfermagem uma vez que esta é uma profissão de ajuda e que em qualquer ação de enfermagem ocorre uma interação.

$\mathrm{Na}$ enfermagem, é de consenso preconizar uma prestação de assistência integral ao indivíduo, sendo este um discurso não só dos enfermeiros assistenciais como também dos enfermeiros docentes. Em contrapartida, alguns pesquisadores na área detectaram que os enfermeiros identificam e atendem principalmente as necessidades do plano físico ou psicobiológico (KAMIYAMA, 1979; PAIM 1979). Esta também tem sido a nossa percepção. Dentre as causas mencionadas pelos enfermeiros e que os levariam a ter dificuldades na relação com o paciente, FERREIRA \& HISAMITSU (1993) encontraram: a falta de preparo acadêmico, a falta de vivência, o não saber lidar com o estresse frente à doença e/ou morte e o medo de se envolver... Estes resultados nos levam a pensar que, provavelmente, existam alguns problemas no preparo do enfermeiro para a relação com o paciente.

Ao analisarmos o marco conceitual desta relação encontramos como aspecto básico, o envolvimento emocional. Este é básico pois, segundo TRAVELBEE (1979), o profissional necessita se envolver emocionalmente se deseja estabelecer uma relação com o paciente ou com qualquer outro ser humano. Também STEFANELLI et al. (1982) afirmam que o envolvimento emocional é um aspecto vital na relação terapêutica com o paciente. Neste momento consideramos importante conceituarmos o envolvimento emocional.

Segundo TRAVELBEE (1979), envolvimento emocional é a capacidade de transcender-se a si mesmo e interessar-se por outra pessoa sem que este interesse nos inabilite. É através do envolvimento que nós nos

\footnotetext{
* Enfermeira Professor Assistente do Departamento de Enfermagem da Universidade Federal de São Carlos - São Paulo
} 
apercebemos do outro, tornando-nos sensíveis à situação que está vivenciando o que nos mobiliza a oferecer a ajuda necessária.

Outro fator levantado nesta conceituação, que certamente é uma condição para o envolvimento, é o princípio de que o envolvimento não deve trazer prejuízos, ou seja, nos inabilitar. Sendo assim, e concordando com TRAVELBEE (1979), entendemos que ele deve ocorrer de forma madura, profissional, com limites a serem obedecidos.

Embora o envolvimento emocional seja considerado como uma condição básica para se estabelecer uma relação segundo TRAVELBEE (1979), há na enfermagem uma política do não envolvimento** sendo este considerado como uma atitude não profissional que traz prejuízo tanto para o paciente quanto para o pessoal de enfermagem. Também MENZIES (1970), ao analisar o serviço de enfermagem de um hospital inglês, detectou uma série de mecanismos que os profissionais deste serviço utilizam para minimizar a ansiedade que o lidar com o paciente suscita, as quais denominou de técnicas de defesa e que, de uma certa forma, também funcionam como política do não envolvimento.

Para essa autora, o indivíduo que ingressa em qualquer profissão que lida com gente precisa desenvolver um distanciamento profissional adequado conseguindo assim aprender a controlar seus sentimentos, refrear um envolvimento excessivo, evitar identificações perturbadoras, manter sua independência profissional contra a manipulação e a solicitação de um comportamento não profissional.

Todavia, partindo do princípio de que deve haver envolvimento emocional na relação com o paciente e que, ao mesmo tempo, o profissional precisa ter conhecimento e habilidades para lidar com tais situações, gostaríamos de entender melhor como esse processo ocorre na prática. Sendo assim nos perguntamos: o que os componentes da equipe de enfermagem pensam sobre o envolvimento emocional em suas relações com o paciente? Acreditam que este envolvimento deve ocorrer? A política do não envolvimento, citada por TRAVELBEE (1979), está presente também em nosso meio? Partindo destes questionamentos, definimos o objetivo deste trabalho.

\section{OBJETIVO}

Analisar o que os componentes da equipe de enfermagem pensam sobre o envolvimento emocional em suas relações com o paciente.

\section{METODOLOGIA}

\subsection{Tipo, método e local da pesquisa}

Para a realização desta pesquisa, optamos, como conduta metodológica, por uma abordagem qualitativa do tipo estudo de caso. A mesma foi realizada em um hospital geral filantrópico situado numa cidade do interior do estado de São Paulo.

\section{2. População e amostra}

A população deste estudo foi composta por 55 funcionários que integravam, no momento, a equipe de enfermagem do hospital acima referido, correspondendo a aproximadamente $20 \%$ da população total da equipe de enfermagem da instituição. Como se trata de uma pesquisa qualitativa, não estabelecemos amostra de representação probabilística, apenas coletamos os dados daqueles que se dispuseram para tal, tentando abranger o maior número possível de pessoas, acreditando que com isso teríamos uma maior riqueza de informações. Sendo assim, a população deste estudo ficou constituída por: cinco enfermeiros, sete auxiliares de enfermagem e quarenta e três atendentes de enfermagem

Os enfermeiros se encontram aqui representados em aproximadamente $60 \%$ do total presente na instituição, enquanto que a maior representatividade dos atendentes de enfermagem se justifica pelo fato de serem estes, ainda em maior número, a prestarem assistência no hospital pesquisado.

\section{3 Coleta dos dados}

Os dados foram colhidos no $2^{\circ}$ semestre de 1994 , através da aplicação de um formulário (anexo), contendo dados de identificação do informante e duas questões abertas. O conteúdo das questões, centrou-se em o que os elementos da equipe de enfermagem pensam sobre o envolvimento emocional, se eles consideram que deve haver envolvimento na relação com o paciente e suas justificativas mediante tais afirmações/negações. $\mathrm{O}$ formulário foi apresentado pelas pesquisadoras, sendo preenchidos pelos próprios informantes, no mesmo momento.

\section{4. Análise dos dados}

Os dados colhidos foram submetidos à análise

** Para a autora a política do não envolvimento tem um caráter de princípio na enfermagem, sendo justificado pelos seguintes argumentos: quanto maior for o envolvimento emocional menos profissional será a relação; o envolvimento emocional leva a identificação excessiva com o paciente; o envolvimento emocional não é terapêutico para o paciente e é prejudicial a enfermeira; a pessoa que se envolve é considerada incapaz e inapta (TRAVELBEE, 1979) 
através das categorias que emergiram dos discursos produzidos. Esta análise foi feita num primeiro momento, separadamente por categoria funcional da equipe de enfermagem, permitindo assim que, num segundo momento, pudéssemos analisar o seu conjunto.

Por outro lado, também foi adotada essa estratégia por considerarmos que o conteúdo das entrevistas representava o saber-fazer deste aspecto básico da relação com o paciente. Dessa forma, a análise, além de nos dar uma visão de como a relação com o paciente vem se processando na prática, possibilitaria também, verificar a concepção dos vários elementos da equipe de enfermagem em relação ao envolvimento emocional com o paciente.

Assim, na análise dos dados será apresentada, primeiramente, a visão dos enfermeiros sobre o envolvimento emocional e em seguida, a visão dos auxiliares e atendentes, representando a concepção que a equipe de enfermagem da instituição tem do envolvimento emocional, como será visto a seguir.

\section{ENVOLVIMENTO EMOCIONAL PARA A EQUIPE DE ENFERMAGEM}

\subsection{O envolvimento emocional para os enfermeiros}

Ao analisarmos as falas dos enfermeiros consultados, percebemos que para eles o envolvimento emocional com o paciente, em alguns momentos, é algo que não deve ocorrer, uma vez que é doloroso, traz mais um problema para resolver e atrapalha o serviço, isto porque eles acreditam que acabam se dedicando muito a um paciente deixando os demais sem atendimento. Essas percepções podem ser vistas através das seguintes falas:

Para o profissional de saúde se envolver emocionalmente é muito doloroso, pois nem sempre as coisas tomam o rumo que nós queremos, se acontece o pior sofremos muito ...

Uma relação difícil e inaceitável pois quando se envolve emocionalmente com o doente passamos a ter mais um problema ou seja, a doença dele e a nossa doença (estado emocional)

... quando acontece o envolvimento emocional atrapalha o meu serviço, pois acabo oferecendo a esse paciente quase uma dedicação exclusiva deixando as outras coisas de lado.

Percebemos assim que para o enfermeiro o envolvimento é algo que não deve ocorrer, pois ao contrário do preconizado por TRAVELBEE (1979), como envolvimento emocional, ou seja, a capacidade de a pessoa interessar-se pelo outro sem que este interesse a incapacite, os enfermeiros o consideram prejudicial para si mesmos, para o paciente e para o serviço.
Já, em outro momento, encontramos nos discursos dos enfermeiros aspectos positivos do envolvimento emocional que consideram ser muito interessante e muito difícil não se envolver com o estado emocional do paciente. No entanto, podemos perceber que as falas não traduzem a essência do envolvimento emocional como preconizado por TRAVELBEE (1979), pois segundo ela a enfermeira necessita comprometer-se emocionalmente se aspira a estabelecer uma relação com um paciente ou com qualquer outro ser humano.

Embora as colocações dos enfermeiros traduzam, num certo sentido, aspectos positivos no se envolver, as falas que se seguem a estas também,como nas anteriores, representam a nosso ver um despreparo dos enfermeiros, pois o envolvimento é visto não como uma questão básica da relação, mas como uma forma de orientar o paciente ou mesmo como uma medida terapêutica. Assim verbalizam :

... é muito interessante ... porque além de supervisionar eu procuro orientá-los em várias questões de suas vidas fora dos hospitais.

É muito dificíl não se envolver com o estado emocional do paciente, mas às vezes que isso ocorre é para se usar isso como uma medida terapêutica.

Tais dados nos levam a inferir que esses enfermeiros estão com dificuldades de estabelecer em sua prática um envolvimento emocional maduro, profissional e terapêutico com o paciente o que pode ser justificado, talvez, por um despreparo acadêmico e por falta de espaços para discussão de suas relações. Também FERREIRA (1992) relata em seu trabalho queixas semelhantes dos enfermeiros quanto às dificuldades encontradas ao assistirem emocionalmente o paciente.

Frente aos resultados obtidos não é de se estranhar que três dos cinco enfermeiros consultados dissessem que não deve haver envolvimento na relação com o paciente. Os que não negaram também não afirmaram, mas responderam que dependia do tipo de envolvimento. Sendo assim, analisaremos com mais detalhes as justificativas dadas pelos enfermeiros para o não envolvimento.

\subsubsection{Por que não se envolver com o paciente}

Para TRAVELBEE (1979), a política do não envolvimento tem alcançado o caratér de princípio em enfermagem, sendo que os que adotam esta política justificam-na considerando que:

- quanto maior for o envolvimento emocional, menos profissional será a relação e vice-versa;

- o envolvimento emocional leva o enfermeiro a identificarse excessivamente com o paciente (esta afirmação considera o envolvimento imaturo);

- a pessoa que se envolve é considerada inapta e incapaz 
pois se compadece demais do paciente sendo excessivamente sensível e, portanto, não poderá ser verdadeiramente útil a ele;

- o envolvimento emocional não é terapêutico para o paciente mas destrutivo para o crescimento da enfermeira.

Ao analisarmos as falas dos enfermeiros encontramos muitos dos aspectos citados por TRAVELBEE. Assim os enfermeiros se expressaram:

Quando vemos o paciente como amigo ficamos defasados do nosso profissionalismo ...

... se ele misturar o seu estado emocional com o do paciente não consegue produzir e ainda consegue assimilar em si um estado de depressão, pois passará a se comparar com todos os problemas do paciente ...

Além disso, os enfermeiros vêem outros efeitos negativos do envolvimento, como a perda da objetividade, do senso crítico, o que impossibilita a execução de determinados cuidados e pode também piorar o estado emocional do paciente. Podemos ver estes aspectos nos discursos a seguir:

... passamos a enxergar o paciente como se fosse dar tudo certo com ele, esquecendo da gravidade do problema dele e deixando passar coisas críticas em seu estado geral; em resumo perdemos a frieza e o senso crítico.

... dificultando o tratamento e não dando tudo de si pois sempre tem pena. Exemplo uma aspiração adequada: é totalmente traumatizante.

Porque, algumas vezes podemos atrapalhar e de vez o paciente melhorar ele pode piorar o seu estado emocional.

Vemos nestas falas a expressão do medo que a proximidade com o paciente pode trazer acarretando malefícios para ambos, profissional e paciente. Daí a necessidade de se manter alguma distância do paciente, desenvolvendo uma certa "frieza" para poder prestar o cuidado necessário.

\subsection{O envolvimento emocional para os auxiliares de enfermagem}

Um pouco diferente dos relatos dos enfermeiros, os formulários respondidos pelos auxiliares se apresentaram bastante suscintos quanto ao conteúdo das respostas e bastante pobre quanto às significações das mesmas. Acreditamos que talvez isso possa ser decorrente tanto da dificuldade na expressão de suas opiniões, quanto da formação e atuação tecnicista desses profissionais.

No entanto, percebemos que repetindo o discurso dos enfermeiros, cinco dos sete consultados consideram que não deve haver envolvimento. Eles também utilizam a política do não envolvimento, acrescentando como motivos para isso, além de alguns dos já citados pelos enfermeiros, o fato de que isso atrapalharia a sua vida extra-hospitalar. Isto pode ser visto nas seguintes colocações:

Se nos envolvermos emocionalmente com todos os pacientes levaremos para casa muitos problemas e consequências.

Há determinados envolvimentos emocionais os quais acabam dificultando nosso meio externo, longe da instituição.

Vemos, assim, que estes achados, ou seja, a reprodução do mesmo discurso dos enfermeiros, podem ter sua origem no fato de que o ensino, nos cursos de auxiliar de enfermagem, é ministrado por enfermeiros, embora não possamos afirmar que isto ocorra neste caso. Dessa forma, o discurso/prática dos princípios do não envolvimento podem ter sido transmitidos durante o curso ou mesmo na prática diária da assistência de enfermagem.

\subsection{O envolvimento emocional para os atendentes de enfermagem}

Ao analisarmos as falas dos atendentes de enfermagem, percebemos que estas se apresentam bastante distintas das falas dos demais elementos da equipe de enfermagem, uma vez que encontramos uma grande verbalização de sentimentos caritativos como dó, pena e considerações para com o paciente, que é visto como frágil, carente e necessitado, fato que leva os atendentes a verbalizarem sentimentos de amor, piedade e carinho. Podemos ver melhor isto nas seguintes colocações:

... envolvo demais porque o paciente é carente...

Bastante comovida um pouco de tudo, amor, piedade, consideração acima de tudo.

... porque muitos deles são carentes ...

... o paciente se sentirá melhor por estar sendo bem recebido e amado e importante.

... tem que ser de maneira profissional com atenção respeito e carinho ...

Sinto muita pena do paciente. Sempre tento ajudar.

... a gente sofre juntos mas somos irmãos.

... me sinto como mãe deles.

Podemos inferir que a verbalização de tantos sentimentos humanitários por estes elementos da equipe ocorre em função de eles serem o corpo de trabalhadores da enfermagem que se faz mais presente junto aos pacientes e, portanto, mantém com eles uma maior proximidade. Sabemos ser esta a realidade não só do hospital pesquisado, mas também da maioria das instituições hospitalares do país. MUYLAERT (1992, p. 95) observou em sua pesquisa que "...é com as atendentes 
que os pacientes desabafam, contam seus problemas, enquanto elas lhes dão banho, por exemplo ..."

Apesar das manifestações de sentimentos humanitários, praticamente a metade da amostra de atendentes afirma que não deve haver envolvimento com o paciente enquanto a outra metade afirma que deve. Assim, analisaremos primeiramente os motivos para o envolver-se com o paciente para, em seguida, analisarmos o não envolvimento.

\subsubsection{Por que se envolver com o paciente}

Vejamos a seguir, nas falas dos atendentes, os motivos citados por eles para que haja envolvimento emocional:

Você acaba entendendo o paciente sentindo o que ele sente.

O paciente precisa de um carinho profissional porque ele é carente, mas sem deixar ele confundir e misturar as coisas ...

Porque se não houver um pouco de amizade entre ambas as partes, é difícil conhecermos sobre as queixas do paciente.

O convívio diário faz com que o paciente seja visto como familiar e aí se apega.

Porque fica mais próximo e favorece a ajuda.

Por sentir a mesma dor do paciente.

... se eu não me emocionar não vou conseguir atender bem.

Se não usarmos o lado emocional fica como se não lidassemos com pessoas e sim com máquinas.

Podemos, portanto, perceber que tais discursos nos revelam que o envolvimento é visto como essencial, pois só assim o profissional consegue perceber as dificuldades do paciente favorecendo a ajuda. Além disso, parece-nos que para alguns atendentes o envolvimento deve ocorrer com limites sendo, portanto, um envolvimento maduro. Também, algumas vezes, as falas trazem um sentimento empático em relação à dor do paciente. Lembramos que, para ROGERS \& ROSEMBERG (1977, p. 72), estado de empatia consiste em "aperceber-se com precissão do quadro de referências interno de outra pessoa, juntamente com os componentes emocionais e os significados a ele pertencentes, como se fôssemos a outra pessoa, sem perder jamais a condição de como se".

Chamou-nos a atenção o discurso de uma atendente de enfermagem, dentre os que afirmaram que deve haver envolvimento, por considerá-lo inevitável, acontecendo sem que a gente perceba, mas considerando-o, ao mesmo tempo, como uma limitação humana quando afirma :... enfim somos humanos e temos nossas fraquezas. Isto a nosso ver, deixa transparecer um certo sentimento de culpa por se envolver com o paciente, o que também foi percebido estar sutilmente presente em alguns outros discursos.

No entanto, a outra metade da amostra (22 atendentes) considera que não deve haver envolvimento relatando os vários motivos, o que será discutido a seguir.

\subsubsection{Por que não se envolver com o paciente}

Os motivos mencionados pelos atendentes para o não envolvimento estão relacionados com o fato de este atrapalhar o trabalho, o tratamento do paciente, gerar sofrimento psíquico do profissional, traduzindo-se, portanto, em uma atitude não profissional, como podemos ver nas seguintes falas:

Se você emocionar com o paciente talvez não consiga trabalhar.

Porque me atrapalha. Eu já chorei muito por sentir pena.

Se você se envolver emocionalmente, você talvez não consiga fazer o seu trabalho.

Não deve se envolver porque vou atrapalhar o tratamento do paciente.

Não devemos misturar os problemas dos pacientes com os da gente.

Porque com uma emoção muito profunda não daremos os cuidados mais radicais que precisa.

Porque envolvendo-se emocionalmente o lado profissional acaba sendo prejudicado porque a razão tem que estar acima da emoção.

Vemos aqui uma semelhança com os motivos citados pelo restante da equipe que recai novamente na política do não envolvimento utilizada pela enfermagem e que já foi discutida anteriomente.

Resta-nos agora, segundo a proposta inicial, fazer uma análise global do comportamento da equipe de enfermagem frente a esta questão.

\section{5- ANÁLISE E SÍNTESE}

Iniciamos este trabalho perguntando o que os componentes da equipe de enfermagem de um hospital geral pensam sobre o envolvimento emocional em suas relações com o paciente. Ao analisarmos os discursos dos vários seguimentos da equipe de enfermagem pudemos verificar que, como TRAVELBEE (1979) afirma, existe na enfermagem uma política do não envolvimento. Ao contrário do esperado, o enfermeiro é o que mais verbaliza o não envolvimento com o paciente seguido dos auxiliares. Por outro lado, encontramos nos discursos dos atendentes muitas expressões que nos traduzem um maior envolvimento (embora metade deles também afirme que este não deve haver). 
Estes achados nos surpreenderam uma vez que esperávamos que o enfermeiro, pela sua formação acadêmica, deveria possuir um maior conhecimento da relação com o paciente. Já os atendentes, dos quais esperávamos um menor conhecimento, transmitiram-nos, além de um maior envolvimento, um saber que vem de encontro aos pressupostos teóricos.

Estas constatações nos levam a confirmar a nossa dúvida inicial de que, provavelmente, haja problemas no preparo do enfermeiro para a relação com o paciente. Sabemos que o ensino da relação de ajuda ou terapêutica tem sido mais enfatizado na Disciplina Enfermagem Psiquiátrica entendida, equivocadamente, como a responsável por este enfoque. Por outro lado, esta disciplina está colocada, muitas vezes, no final da grade curricular, o que leva à discussão tardia da relação enfermeiro-paciente, impedindo que o aluno aplique tais conhecimentos em outras áreas.

FRAGA et al. (1986, p. 97), quando analisam o ensino do relacionamento terapêutico, no curso de graduação, também encontraram como uma de suas dificuldades situações semelhantes, sugerindo ainda que "o relacionamento interpessoal de ajuda, embora instrumento fundamental em Enfermagem na Saúde Mental e Psiquiátrica deve ser incorporado ao longo do currículo."

Porém, a nosso ver, esta não é a única dificuldade na formação do enfermeiro para a relação, uma vez que outros autores também levantaram que o ensino reforça o não envolvimento com o paciente quando ensina que o enfermeiro deve controlar suas emoções já que elas interferem negativamente no desempenho profissional (TAKAHASHI, 1991;FERREIRA, 1994).

Acreditamos ser importante, também, analisar o discurso do não envolvimento presente em todos os seguimentos da equipe de enfermagem. Sabemos que o envolvimento leva a uma aproximação entre o profissional e o paciente. Porém esta aproximação, segundo os relatos do pessoal de enfermagem, além de outros efeitos negativos gera sofrimento psíquico verbalizado como sendo muito doloroso, já chorei muito, a gente sofre muito, a gente sofre juntos, levando a um estado depressivo e a sentimentos de culpa por se envolverem com o paciente.

A nosso ver, como defesa contra estes sentimentos, os elementos da equipe de enfermagem reagem com o distanciamento. Este, segundo MENZIES (1970), é uma técnica de defesa que o serviço de enfermagem utiliza como proteção contra a ansiedade gerada pelo contato com o paciente. Outros exemplos são: a despersonalização tanto do profissional quanto do paciente; a categorização e negação da importância do indivíduo que é transformado pela equipe no paciente do leito 10 ou o cardiopata; ou ainda a fragmentação do cuidado através do desenvolvimento de listas de tarefas.
Também DEJOURS (1989, p.98), pesquisador da psicopatologia do trabalho mais recentemente denominada psicodinâmica do trabalho, identifica tais técnicas de defesa as quais denomina "defesas coletivas". Estas, segundo este autor, são "elaboradas contra as diferentes formas de sofrimento e sobretudo contra o medo que resulta do trabalho."

Outro efeito negativo do envolvimento com o paciente, mencionado por todas as categorias e também aceito por nós, é o de que se envolver implica em perceber o outro como pessoa, não como objeto. Perceber o outro enquanto pessoa, segundo alguns consultados atrapalha o trabalho da enfermagem, pois o profissional se dedica a um paciente e deixa os outros, bem como os leva a não executarem as tarefas necessárias ao cuidado, por sentirem pena do paciente, o que acarreta perda de objetividade.

Essa análise vem de encontro ao pensamento de TESTA ( 1992), profissional da área da saúde, que, ao experenciar o estado de paciente internado, sentiu que a equipe de saúde o transformou em um objeto, ou seja, eliminou sua subjetividade e individualidade. Ao analisar esta objetualização, o autor encontrou outros estudiosos da área que afirmam ser ela necessária para alcançar a eficácia do procedimento terapêutico, o que também vem de encontro ao mencionado por vários integrantes da equipe de enfermagem que foram consultados.

No entanto, para TESTA (1992), esta objetualização, embora aceita como necessária por alguns profissionais da saúde, traz o risco de se cometer erros pela excessiva confiança gerada nos dados objetivos conseguidos apenas com os diversos aparelhos que registram as funções do paciente. É desprezada, neste caso, a individualidade, a singularidade do paciente, que poderia aflorar durante um contato mais próximo.

Finalizando, num contexto de equipe, gostaríamos de comentar a nossa percepção quanto ao discurso dos atendentes que diferente dos demais elementos, verbalizaram sentimentos caritativos, de generosidade e benevolência para com os pacientes. Encontramos nas afirmações de PITTA (1990, p. 77), o que julgamos ser uma explicação para este fato, quando ela coloca que : "o cuidar de uma pessoa doente é inserido num contexto social onde a piedade e a solidariedade são sentimentos socialmente valorizados dentro de uma estratégia de sobrevivência da espécie e de uma certa sociabilidade que tem na harmonia o seu paradígma e na saúde um elemento indissociável a esta harmonia; este cuidar deverá ter um valor de natureza moral e ética que canalize energias e simpatias."

Consideramos, no entanto, que esta não deve ser a única justificativa para explicar a expressão de tais sentimentos uma vez que ela surge somente no grupo de atendentes. Talvez, isto se deva mais ao fato de, como 
mencionado anteriormente, serem estes elementos os que estão mais próximos do paciente, apresentando um maior envolvimento e ao fato de, não tendo passado pelo ensino formal da enfermagem, não terem aprendido a controlar suas emoções.

Frente a estes achados não nos parece fácil prescrever ou ensinar a efetivação do envolvimento emocional com o paciente, uma vez que, pelo que pudemos perceber, a política do não envolvimento é empregada como uma técnica coletiva de defesa, e esta parece ser uma prática comum dos trabalhadores da saúde na instituição hospitalar consultada.

\section{EMOTIONAL INVOLVEMENT TO THE NURSING TEAM: REALITY OR MYTH?}

The present study aims to analyze what the members of the nursing team think about their emotional involvement with the patients during their relationship. Data were collected through the application of an instrument to members of the nursing team (registered nurse, nursing aides and attendants). The analysis was done, at first, separately by functional categories and after that, as a whole. We concluded that, there is in nursing a policy of no involvement with the patients and that the registered nurse is the one that most verbalizes it. One of the negative factors of the involvement with the patient is the psychological suffering of the nursing team members. This leads us to identify the no involvement behavior as a collective defence mechanism against suffering.

KEY WORDS: emotional involvement, therapeutic relationship

\section{EL COMPROMISO EMOCIONAL PARA EL GRUPO DE ENFERMEROS: REALIDAD O MITO ?}

El presente trabajo tiene como objetivo analizar lo que los componentes del grupo de enfermeros de un hospital general piensan sobre el compromiso emocional en sus relaciones con el paciente. Los datos fueron colectados a través de la aplicación de un formulario a varios integrantes del grupo de enfermeros (enfermero y auxiliares de enfermería). Estos fueron analizados en un primer momento separados por categorías funcionales, y en un segundo momento, se hizo un análisis global. Al final fue posible, concluir que existe en el relacionamiento del enfermero una política no comprometerse, siendo el enfermo al contrario del esperado, el que mas expresa este hecho. Entre los factores considerados negativos, que acarrea el compromiso afectivo está el sufrimiento psíquico de los integrantes del grupo. Esto nos lleva a identificar el no compromiso con el paciente como una técnica colectiva de defesa contra el sufrimiento.

TÉRMINOS CLAVES: compromiso emocional, relacionamiento terapéutico

\section{REFERÊNCIAS BIBLIOGRÁFICAS}

01. DEJOURS, C. Introdução à psicopatologia do trabalho. Tempo Social. Rev. Sociol. USP., v. 1, n 2, p. 97-103. 1989

02. , N.M.L.A. A assistência emocional: dificuldades do enfermeiro. Rev. Baiana Enfermagem, v.5, n.1, p.30-41, out. 1992.

03. _ N.M.L.A. A difícil convivência com o câncer: um estudo das emoções na enfermagem oncológica. São Paulo, 1994. 109p. Dissertação (Mestrado) - Pontífica Universidade Católica de São Paulo.

04. FERREIRA, N.M.L.A.; HISAMITSU, C. O enfermeiro frente as manifestações emocionais do paciente hospitalizado. Acta Paul. Enfermagem, v. 6, n.1/4, p. 16-23, 1993.

05. FRAGA, M. N.O. et al. Ensino do relacionamento terapêutico em enfermagem. Psiquiátrica: dificuldades e perspectivas. Rev. Bras. Enfermagem, v. 39, n. 2/3. p. 94-102. 1986.
06. KAMIYAMA, Y. A assistência centrada na identidade social, aspectos do cuidado de enfermagem ao paciente com hepatite infecciosa. São Paulo, 1979. 179p. tese (Livredocência) - Escola de Enfermagem, Universidade de São Paulo.

07. MENZIES, I.E.P. O funcionamento das organizações como sistemas sociais de defesa contra a ansiedade. Trad. Aracky M. Rodrigues. São Paulo, 1970. 56p. (mimeo)

08. MUYLAERT, M.A.O. O psicólogo no hospital geral: a incomoda escuta da "queixa do desejo". São Paulo, 1992. 118p. Dissertação (Mestrado)- Pontífica Universidade Católica de São Paulo.

09. PAIM, L. Algumas considerações de enfermagem sobre necessidades psico-espirituais dos pacientes. Rev. Bras. Enfermagem, v. 23, n. 2, p.160-166, 1979. 
10. PITTA, A. Hospital: dor e morte como ofício. São Paulo: Hucitec, 1990. 198p.

11. ROGERS, C.R.; ROSEMBEG, R.L. A pessoa como centro. São Paulo: EPU/EDUSP, 1977. 228p.

12. STEFANELLI, M.C.; ARANTES, E.C.; FUKUDA, I.M.K. Aceitação, empatia e envolvimento emocional no relacionamento enfermeiropaciente. Rev.Esc.Enfermagem da USP, v. 16, n. 3, p. 245-53, 1982.
13. TAKAHASHI, E.I.V. A emoção na prática de enfermagem: relatos por enfermeiros de U.T.I e U.I. São Paulo, 1991. 231p. Tese (Doutorado) Escola de Enfermagem, Universidade São Paulo.

14. TESTA, M. O hospital: visão desde o leito do paciente. Rev. Saúde Mental Coletiva. v.1, n.1, p.47-54,1992

15. TRAVELBEE, J. Intervención en enfermeria psiquiátrica. Washington: Organização Panamericana de la Salud, 1979. 257p. 
ANEXO

\section{FORMULÁRIO}

1.FUNÇÃO(Assinale com um $x$ a alternativa correspondente)

( ) atendente de enfermagem

( ) auxiliar de enfermagem

( ) técnico de enfermagem

( ) enfermeiro

\section{QUESTÕES}

- O que você pensa sobre o envolvimento emocional com o paciente?

-Você considera que o profissional de enfermagem deve ou não deve se envolver emocionalmente com o paciente? ( ) $\mathrm{Sim}$ ( ) Não

Porque 